\title{
Radiochemotherapy with Paclitaxel for Recurrent Previously Irradiated Squamous Cell Carcinoma of the Head and Neck
}

\author{
DIRK RADES ${ }^{1}$, DANIEL SEIDL ${ }^{1}$, BARBARA WOLLENBERG ${ }^{2}$, STEVEN E. SCHILD ${ }^{3}$ and SAMER G. HAKIM ${ }^{4}$ \\ Departments of ${ }^{1}$ Radiation Oncology, ${ }^{2}$ Oto-Rhino-Laryngology and Head and Neck Surgery and Oral and \\ ${ }^{4}$ Maxillofacial Surgery, University of Lübeck, Lübeck, Germany; \\ ${ }^{3}$ Department of Radiation Oncology, Mayo Clinic, Scottsdale, AZ, U.S.A.
}

\begin{abstract}
Background/Aim: Locoregional recurrences of squamous cell carcinoma of the head and neck (SCCHN) are difficult to treat. If radiotherapy was included in the primary treatment, another curative course of radiotherapy incurs substantial risk of complications. Results of re-irradiation can be improved by concurrent chemotherapy. Patients and Methods: Radiotherapy with low doses per fraction twice daily and paclitaxel were applied in four patients with recurrent SCCHN. Radiotherapy was administered with doses of 30-36 Gy and doses per fraction of 1.5 Gy twice daily. Concurrent chemotherapy consisted of 20-25 $\mathrm{mg} / \mathrm{m}^{2}$ paclitaxel twice per week. Overall 1-year locoregional control following re-irradiation was $25 \%$. One-year locoregional control rates were $75 \%$ inside the re-irradiated region and 50\% outside the re-irradiated region. Distant metastases did not occur. One-year overall survival following re-irradiation was 75\%. Toxicity did not exceed grade 2 . Conclusion: Re-irradiation plus concurrent paclitaxel appeared well-tolerated and resulted in promising outcomes.
\end{abstract}

Locoregional recurrence of a squamous cell carcinoma of the head and neck (SCCHN) is reported in up to $50 \%$ of patients with a locally advanced tumor (stage III/IV) and often associated with poor prognoses (1-3). The most appropriate treatment depends on tumor size, localization and presence of distant metastasis and is, therefore, difficult to make. This is particularly true if radiotherapy or radiochemotherapy were part of the initial treatment of the primary SCCHN. Although salvage surgery alone in the irradiated regions has

Correspondence to: Professor Dirk Rades, MD, Department of Radiation Oncology, University of Lübeck, Ratzeburger Allee 160, 23538 Lübeck, Germany. Tel: +49 4515006661, Fax: +49 4515003324, e-mail: rades.dirk@gmx.net

Key Words: Squamous cell carcinoma of the head and neck, locoregional recurrence, re-irradiation, radiochemotherapy, paclitaxel. been reported to achieve reasonably good results in view of local control and overall survival, it is generally associated with an increased risk of infections, bleeding and wound healing problems (4-6). Furthermore, complete in sano resection is difficult to achieve in extended recurrent lesions close to critical structures like major cervical blood vessels and relevant neuronal structures. Radiotherapy alone or following tumor debulking is a viable option. However, a second series of radiotherapy to the same region cannot be safely performed with similarly high curative doses as the tolerance doses of the normal tissues have already been administered $(7,8)$.

A randomized trial of definitive non-surgical treatment for locally advanced SCCHN in primary tumors compared two modalities, 70.6 Gy plus 7 Gy (about 10\%) and 70.6 Gy plus concurrent chemotherapy (9). Locoregional control rates at five years were $37.4 \%$ and $49.9 \%$, respectively $(p=0.001)$. Thus, the addition of chemotherapy was more effective than another $10 \%$ of radiation dose in patients with SCCHN. This synergistic effect is of particular importance for the reirradiation of recurrent SCCHN, since a second full curative dose is not possible.

Cisplatin is the most commonly used chemotherapeutic agent for SCCHN. However, cisplatin can lead to significant side-effects, including nausea/vomiting, ototoxicity and renal failure (10). The latter toxicity represents the major limiting factor in patients with recurrent SCCHN, particularly in elderly patients or in those with reduced renal function. Taxanes have shown efficacy as part of combined platinumbased chemotherapy regimens for treatment of SCCHN (11). In several studies, monotherapy with paclitaxel has been proven to be effective and well-tolerated in patients with head and neck cancer, including nasopharynx cancer (12-16). Thus, paclitaxel appears a viable option for the radiochemotherapy of recurrent SCCHN.

Another important aspect to be considered during reirradiation for recurrent $\mathrm{SCCHN}$ is the dose per fraction. In general, lower doses per fraction are associated with less late radiation toxicity $(17,18)$. In contrast to tumor cells, 
normal tissue cells generally recover from irradiation after an interval of 6-8 h. Therefore, it appears reasonable to irradiate patients with a recurrent SCCHN twice daily with doses per fraction below the conventional dose of 1.8-2.0 Gy and with an interval of 6-8 $\mathrm{h}$ between the two fractions allowing the normal tissue, but not the tumor cells, to recover in a relevant manner (19). In the present series of patients requiring re-irradiation for recurrent $\mathrm{SCCHN}$, a combination of radiotherapy with low doses per fraction twice daily and concurrent chemotherapy with paclitaxel was applied.

\section{Patients and Methods}

The data of four patients, one woman and three men, treated with re-irradiation and concurrent chemotherapy with paclitaxel for recurrent SCCHN were retrospectively analyzed. Initially, two patients had $\mathrm{pT} 1 \mathrm{pN} 2 \mathrm{~b}$ oropharynx cancer, one patient pT3pN0 hypopharynx cancer and one patient $\mathrm{pT} 1 \mathrm{pN} 1$ larynx cancer. In all patients, the initial treatment included surgery (complete resection) followed by $60 \mathrm{~Gy}$ in 30 fractions of radiotherapy. Radiotherapy was supplemented by cetuximab in one patient with pT1pN2b oropharynx cancer. After a median interval of 50.5 months (range=20-74), all four patients had developed locoregional recurrence. In three patients, it was a recurrence of the primary tumor (rT4N0) and in one patient a contra-lateral lymph node recurrence $(\mathrm{rTxN} 2 \mathrm{~b})$. Age at the time of the recurrence ranged from 46 to 76 years.

The treatment for the locoregional recurrence included concurrent radiochemotherapy with paclitaxel. Three patients underwent upfront microscopically incomplete (R1) resection. Radiotherapy was performed with a modern linear accelerator (Varian Medical Systems, Palo Alto, CA, USA). Treatment was administered as volumetric modulated arc therapy (VMAT). The treatment volume encompassed the region of the locoregional recurrence plus a margin of 2-3 cm. Total doses were 30-36 Gy with doses per fraction of $1.5 \mathrm{~Gy}$ given twice daily, five days per week. Concurrent chemotherapy consisted of $20-25 \mathrm{mg} / \mathrm{m}^{2}$ of paclitaxel administered twice per week. Twenty to $25 \mathrm{mg} / \mathrm{m}^{2}$ of paclitaxel twice weekly is believed to result in better radiosensitizing and less toxicity than $45-50 \mathrm{mg} / \mathrm{m}^{2}$ weekly. A similar regimen was used as a radiosensitizer in organ sparing treatment of urinary bladder cancer (20). In the present series, paclitaxel was administered intravenously (i.v.) as bolus infusion over $1 \mathrm{~h}$. Premedication included i.v. administration of clemastine (2 mg), granisetron (1 mg) and dexamethasone $(8 \mathrm{mg})$.

Investigated end-points included freedom from a second locoregional recurrence, metastases-free survival, overall survival and toxicities. The time to second locoregional failure, time to metastases and time to death were referenced from the time of the diagnosis of the first locoregional recurrence. For the corresponding analyses, the Kaplan-Meier method was used. Investigated toxicities included oral mucositis, radiation dermatitis, nausea/vomiting, hematotoxicity, renal toxicity, ototoxicity, xerostomia, lymph edema, subcutaneous cervical fibrosis and peripheral polyneuropathy (PNP). The toxicities were assessed according to Common Terminology Criteria of Adverse Events (CTCAE) version 4.0 .

\section{Results}

The overall 1-year locoregional control rate following reirradiation was $25 \%$ (Figure 1). Median time to a second locoregional recurrence was 8.5 months. Two recurrences occurred outside the area of re-irradiation just above the borders of the re-irradiation fields. The 1-year rates of locoregional control were $75 \%$ inside the re-irradiated region (in-field control, Figure 2) and 50\% outside the re-irradiated region (out-field control, Figure 3). Distant metastases did not occur during the period of follow-up (median=14.5). Thus, the 1-year metastases-free survival rate was $100 \%$. The 1-year overall survival rate following re-irradiation was $75 \%$ (Figure 4) and the median survival time was 14.5 months. The outcomes of the patients following re-irradiation are summarized in Table I.

Acute and late toxicities were mild and did not exceed grade 2 according to CTCAE version 4.0. The toxicity rates are summarized in Table II.

\section{Discussion}

Considerable improvement has been achieved regarding the primary treatment of locally advanced SCCHN (21-24). However, more than $50 \%$ develop a locoregional recurrence (1-3). For such locoregional recurrence complete resection is difficult to achieve in the vast majority of patients and radiotherapy is required either alone or following surgery. If radiotherapy was already included in the primary treatment, a second curative dose is often not administered due to a considerable risk of damaging adjacent normal tissues. The risk of radiation-induced late toxicity can be reduced with lower doses per fraction than $1.8 \mathrm{~Gy}(17,18)$. Radiotherapy with doses per fraction of $1.5 \mathrm{~Gy}$ given twice per day allows recovery between the two fractions but does not attenuate the impact on tumor cells. For tumor cells, the two daily fractions may function similar to one fraction of approximately $3 \mathrm{~Gy}$. A dose per fraction of $3 \mathrm{~Gy}$ has a greater biological effect than lower doses, since the biological effect of radiotherapy depends on total dose and dose per fraction $(17,18)$. To increase the effect of re-irradiation in these cases it is recommended to include concurrent chemotherapy $(1-3,25)$. Cisplatin, the most commonly used agent, can be associated with considerable toxicities and is, therefore, not suitable for many patients requiring radiochemotherapy for SCCHN (10). This applies particularly to patients with a locoregional recurrence as these patients often have worse performance status than at the time of the primary treatment. Several alternative agents are available, including cetuximab, mitomycin C plus 5-fluorouracil and taxanes (11). Several studies have shown that paclitaxel is effective for SCCHN (12-16). However, no standard regimen has been established. Dosing regimens range from low doses of $2 \mathrm{mg} / \mathrm{m}^{2}$ given 


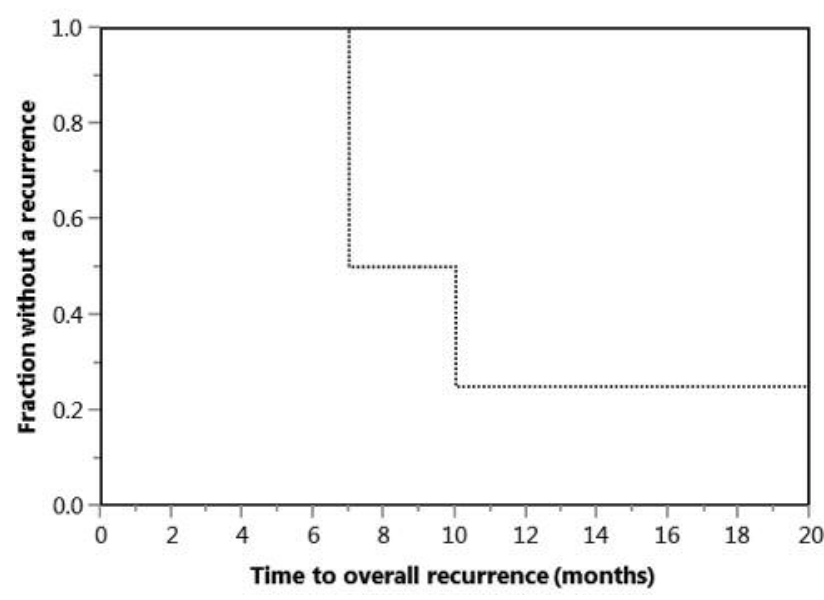

Figure 1. Kaplan-Meier curve for overall locoregional control (locoregional control inside and outside the re-irradiated region).

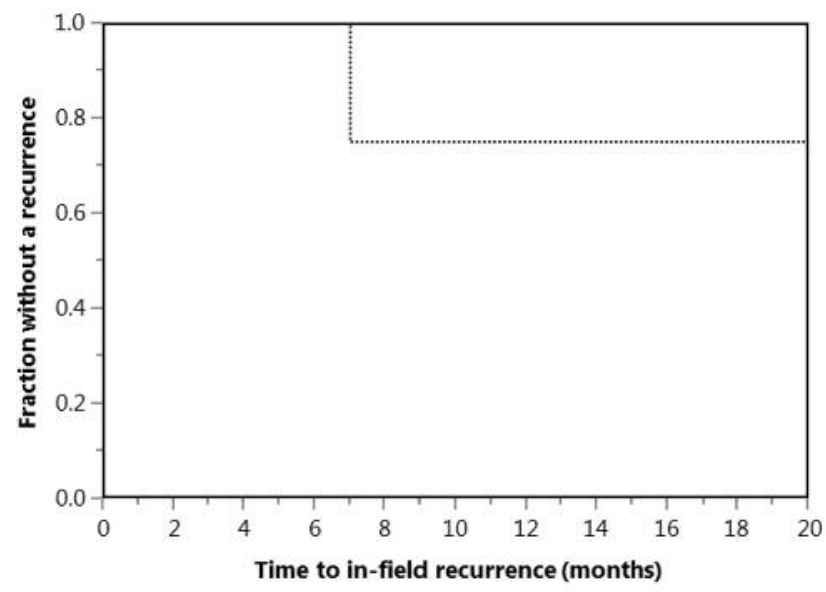

Figure 2. Kaplan-Meier curve for locoregional control inside the reirradiated region (freedom from in-field recurrence).

three times a week to $105-120 \mathrm{mg} / \mathrm{m}^{2}$ given 120 -h continuous infusions. In 2003, a prospective study reported on 26 patients with locally advanced SCCHN and a poor general condition who received radiotherapy plus concurrent low doses of 2 $\mathrm{mg} / \mathrm{m}^{2}$ paclitaxel given three times per week for primary treatment (12). Two-year survival was $46 \%$ and the toxicity profile quite favorable. In a pilot trial of 23 patients with primary unresectable stage IV SCCHN, 70-72 Gy of radiotherapy was combined with two courses of paclitaxel given as 96-h infusion with a median dose of $100 \mathrm{mg} / \mathrm{m}^{2}$ per course (13). Survival and locoregional control rates at 4 years were $37 \%$ and $50 \%$, respectively. All but one patient received the paclitaxel dose as planned. The grade $\geq 3$ late toxicity rate

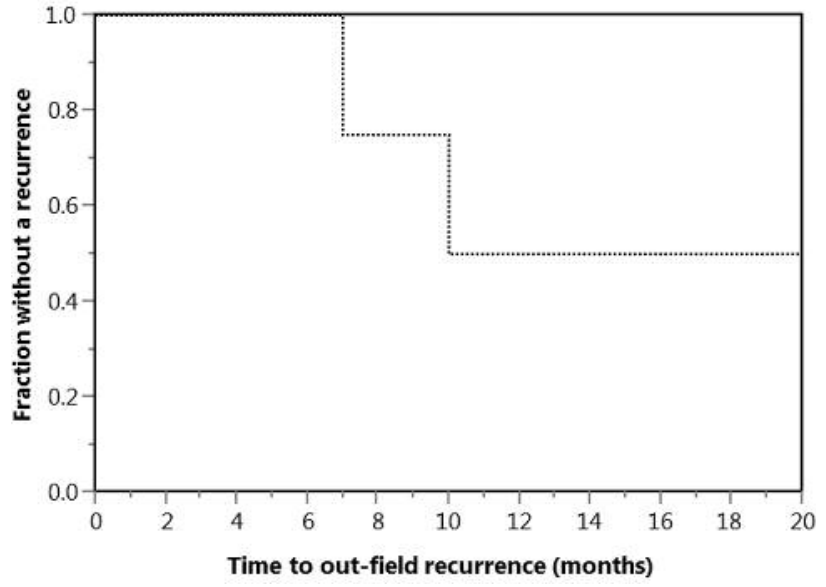

Figure 3. Kaplan-Meier curve for locoregional control outside the reirradiated region (freedom from out-field recurrence).

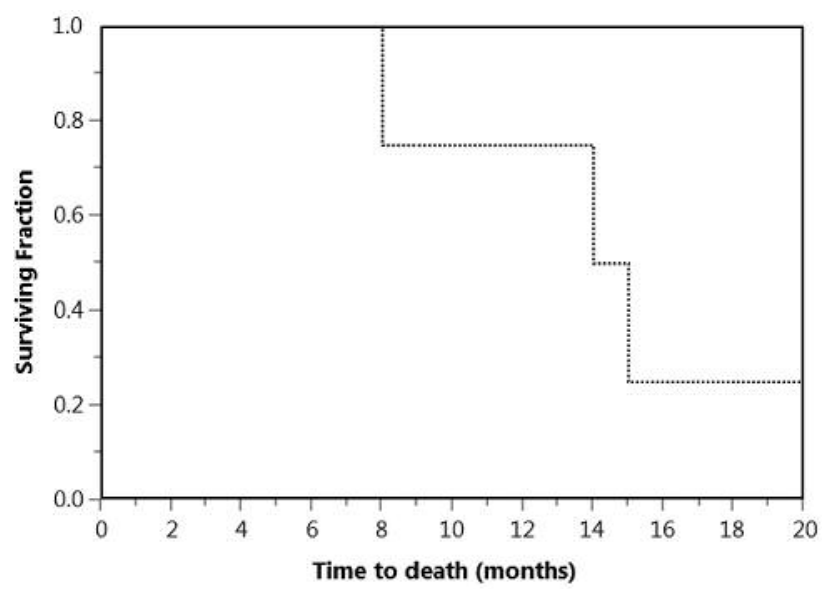

Figure 4. Kaplan-Meier curve for overall survival.

of $18 \%$ was much lower than the grade $\geq 3$ late toxicity rate of $56 \%$ in the trial of the French Head and Neck Oncology and Radiotherapy Group that used carboplatin and 5-fluorouracil (25). In a phase I trial of patients with nasopharynx cancer from China, who received definitive intensity-modulated radiotherapy plus weekly paclitaxel, the maximum tolerated dose of paclitaxel was identified to be $50 \mathrm{mg} / \mathrm{m}^{2}$ per weekly administration (14). In another prospective study, 35 patients with stage III/IV SCCHN received 70.2-72 Gy of radiotherapy plus three courses of paclitaxel started on days 1, 21 and 42 as 120-h infusion (15). Median survival time was 56.5 months; median time to local recurrence was not reached (median follow-up=56.5). The treatment regimen was well- 
Table I. Outcomes of the patients following re-irradiation.

\begin{tabular}{lccc}
\hline Patient & In-field recurrence & Out-field recurrence & Death \\
\hline Patient 1 & Yes (after 7 months) & No & Yes (after 15 months) \\
Patient 2 & No & Yes (after 10 months) & Yes (after 14 months) \\
Patient 3 & No & No & No (alive after 20 months) \\
Patient 4 & No & Yes (after 7 months) & Yes (after 8 months) \\
\hline
\end{tabular}

tolerated. The vast majority of toxicities were grade 1 or 2 . In a randomized phase II trial of 216 patients with locally advanced SCCHN, patients were assigned to radiotherapy with 65 Gy plus either concurrent weekly gemcitabine (100 $\left.\mathrm{mg} / \mathrm{m}^{2}\right)$ or weekly paclitaxel $\left(20 \mathrm{mg} /{ }^{2}\right)(16)$. At two years, the paclitaxel group experienced better progression-free survival (64\% vs. 54\%) and overall survival (67\% vs. 56\%, $p=0.05)$. Paclitaxel was significantly better tolerated with a grade 3 mucositis rate of $24 \%(v s .36 \%, p=0.04)$ and a grade 3 dermatitis rate of $13 \%$ ( $v s .24 \%, p=0.049$ ).

These data show radiochemotherapy with paclitaxel as a single agent as both effective and well-tolerated when used for the treatment of patients with locally advanced SCCHN. Therefore, paclitaxel was used in the present series of patients who required re-irradiation plus chemotherapy for recurrent SCCHN in whom cisplatin was not indicated. In this small study, radiochemotherapy, two lower-dose radiation fractions per day in addition to concurrent administration of $20-25 \mathrm{mg} / \mathrm{m}^{2}$ paclitaxel twice per week, was well-tolerated. The vast majority of toxicities were limited to grade 1 and no grade 3 acute or late toxicities were observed. The 1-year overall survival rate of $75 \%$ was greater than in recent re-irradiation studies for recurrent SCCHN. In those studies, 1-year overall survival rates were $33 \%$ with 48 Gy of radiotherapy alone with two daily fractions of 3 Gy (26), 44\% with re-irradiation with cetuximab and $54 \%$ with re-irradiation, including cisplatinbased chemotherapy (27), 53\% with resection plus brachytherapy (28), $62 \%$ with proton-beam radiotherapy plus intra-arterial chemotherapy (29) and $62.5 \%$ with helical tomotherapy (30). In one retrospective study, 1-year overall survival rate was $77 \%$ (31) with three-dimensional conformal radiotherapy, intensity-modulated radiotherapy or helical tomotherapy. In the present study, the in-field control rate at 1 year was $75 \%$, which was well in the range of $44-80 \%$ reported in the previous studies.

In conclusion, in four previously irradiated patients with recurrent SCCHN, re-irradiation with 30-36 Gy $(2 \times 1.5$ Gy per day) plus concurrent paclitaxel $\left(20-25 \mathrm{mg} / \mathrm{m}^{2}\right.$ twice per week) was very well-tolerated and resulted in promising outcome. This case series represents a prerequisite for a phase I/II trial that will be initiated soon.
Table II. Toxicities according to CTCAE version 4.0.

\begin{tabular}{|c|c|}
\hline & $\mathrm{N}$ patients \\
\hline \multicolumn{2}{|c|}{ Oral mucositis } \\
\hline None & 0 \\
\hline Grade 1 & 2 \\
\hline Grade 2 & 2 \\
\hline \multicolumn{2}{|c|}{ Radiation dermatitis } \\
\hline None & 0 \\
\hline Grade 1 & 4 \\
\hline Grade 2 & 0 \\
\hline \multicolumn{2}{|l|}{ Xerostomia } \\
\hline None & 2 \\
\hline Grade 1 & 2 \\
\hline Grade 2 & 0 \\
\hline \multicolumn{2}{|c|}{ Hematotoxicity } \\
\hline None & 1 \\
\hline Grade 1 & 2 \\
\hline Grade 2 & 1 \\
\hline \multicolumn{2}{|c|}{ Nausea/vomiting } \\
\hline None & 4 \\
\hline Grade 1 & 0 \\
\hline Grade 2 & 0 \\
\hline \multicolumn{2}{|c|}{ Renal toxicity } \\
\hline None & 4 \\
\hline Grade 1 & 0 \\
\hline Grade 2 & 0 \\
\hline \multicolumn{2}{|l|}{ Ototoxicity } \\
\hline None & 4 \\
\hline Grade 1 & 0 \\
\hline Grade 2 & 0 \\
\hline \multicolumn{2}{|c|}{ Lymph edema } \\
\hline None & 3 \\
\hline Grade 1 & 1 \\
\hline Grade 2 & 0 \\
\hline \multicolumn{2}{|c|}{ Subcutaneous cervical fibrosis } \\
\hline None & 3 \\
\hline Grade 1 & 1 \\
\hline Grade 2 & 0 \\
\hline
\end{tabular}

\section{Conflicts of Interest}

On behalf of all Authors, the corresponding Author states that there is no conflict of interest related to this study. 


\section{References}

1 Lefebvre JL, Rolland F, Tesselaar M, Bardet E, Leemans CR, Geoffrois L, Hupperets P, Barzan L, de Raucourt D, Chevalier D, Licitra L, Lunghi F, Stupp R, Lacombe D, Bogaerts J, Horiot JC, Bernier $\mathrm{J}$ and Vermorken JB; EORTC Head and Neck Cancer Cooperative Group; EORTC Radiation Oncology Group: Phase 3 randomized trial on larynx preservation comparing sequential $v s$. alternating chemotherapy and radiotherapy. J Natl Cancer Inst 101: 142-152, 2009.

2 Bernier J, Domenge C, Ozsahin M, Matuszewska K, Lefèbvre JL, Greiner RH, Giralt J, Maingon P, Rolland F, Bolla M, Cognetti F, Bourhis J, Kirkpatrick A and van Glabbeke M; European Organization for Research and Treatment of Cancer Trial 22931: Postoperative irradiation with or without concomitant chemotherapy for locally advanced head and neck cancer. N Engl J Med 350: 1945-1952, 2004.

3 Cooper JS, Pajak TF, Forastiere AA, Jacobs J, Campbell BH, Saxman SB, Kish JA, Kim HE, Cmelak AJ, Rotman M, Machtay $\mathrm{M}$, Ensley JF, Chao KS, Schultz CJ, Lee $\mathrm{N}$ and $\mathrm{Fu} \mathrm{KK}$; Radiation Therapy Oncology Group 9501/Intergroup: Postoperative concurrent radiotherapy and chemotherapy for high-risk squamous-cell carcinoma of the head and neck. N Engl J Med 350: 1937-1944, 2004.

4 Goodwin WJ Jr.: Salvage surgery for patients with recurrent squamous cell carcinoma of the upper aerodigestive tract: when do the ends justify the means? Laryngoscope 110(3 Pt 2 Suppl 93): 1-18, 2000

5 Agra IM, Carvalho AL, Pontes E, Campos OD, Ulbrich FS, Magrin J and Kowalski LP: Postoperative complications after en bloc salvage surgery for head and neck cancer. Arch Otolaryngol Head Neck Surg 129: 1317-1321, 2003.

6 Kostrzewa JP, Lancaster WP, Iseli TA, Desmond RA, Carroll WR and Rosenthal EL: Outcomes of salvage surgery with free flap reconstruction for recurrent oral and oropharyngeal cancer. Laryngoscope 120: 267-272, 2010.

7 Emami B, Lyman J, Brown A, Coia L, Goitein M, Munzenrider JE, Shank B, Solin LJ and Wesson M: Tolerance of normal tissue to therapeutic irradiation. Int J Radiat Oncol Biol Phys 21: 109-122, 1991.

8 Marks LB, Yorke ED, Jackson A, Ten Haken RK, Constine LS, Eisbruch A, Bentzen SM, Nam J and Deasy JO: Use of normal tissue complication probability models in the clinic. Int J Radiat Oncol Biol Phys 76(3 Suppl): S10-19, 2010.

9 Budach V, Stuschke M, Budach W, Baumann M, Geismar D, Grabenbauer G, Lammert I, Jahnke K, Stueben G, Herrmann T, Bamberg M, Wust P, Hinkelbein W and Wernecke KD: Hyperfractionated accelerated chemoradiation with concurrent fluorouracil-mitomycin is more effective than dose-escalated hyperfractionated accelerated radiation therapy alone in locally advanced head and neck cancer: final results of the radiotherapy cooperative clinical trials group of the German Cancer Society 95-06 Prospective Randomized Trial. J Clin Oncol 23: 11251135, 2005.

10 De Castro G Jr, Snitcovsky IM, Gebrim EM, Leitão GM, Nadalin W, Ferraz AR and Federico MH: High-dose cisplatin concurrent to conventionally delivered radiotherapy is associated with unacceptable toxicity in unresectable, non-metastatic stage IV head and neck squamous cell carcinoma. Eur Arch Otorhinolaryngol 264: 1475-1482, 2007.
11 Mody MD, Gill HS and Saba NF: The evolving and future role of taxanes in squamous cell carcinomas of the head and neck: A Review. JAMA Otolaryngol Head Neck Surg, 2016, in press.

12 Lövey J, Koronczay K, Remenár E, Csuka O and Németh G: Radiotherapy and concurrent low-dose paclitaxel in locally advanced head and neck cancer. Radiother Oncol 68: 171-174, 2003.

13 Bucci MK, Rosenthal DI, Hershock D, Metz J, Devine P, Kligerman MM and Machtay M: Final report of a pilot trial of accelerated radiotherapy plus concurrent 96-hour infusional paclitaxel for locally advanced head and neck cancer. Am J Clin Oncol 27: 595-602, 2004.

14 Chen CY, Lu TX, Zhao C, Lu LX, Han F and Sun Y: Weekly paclitaxel with concurrent intensity-modulated radiotherapy for nasopharyngeal carcinoma: outcomes of a tolerance trial. Ai Zheng 26: 398-402, 2007.

15 Citrin D, Mansueti J, Likhacheva A, Sciuto L, Albert PS, Rudy SF, Cooley-Zgela T, Cotrim A, Solomon B, Colevas AD, Russo A, Morris JC, Herscher L, Smith S and Van Waes C: Long-term outcomes and toxicity of concurrent paclitaxel and radiotherapy for locally advanced head-and-neck cancer. Int J Radiat Oncol Biol Phys 74: 1040-1046, 2009.

16 Halim AA, Wahba HA, El-Hadaad HA and Abo-Elyazeed A: Concomitant chemoradiotherapy using low-dose weekly gemcitabine versus low-dose weekly paclitaxel in locally advanced head and neck squamous cell carcinoma: a phase III study. Med Oncol 29: 279-284, 2012.

17 Barendsen GW: Dose fractionation, dose rate and iso-effect relationships for normal tissue responses. Int J Radiat Oncol Biol Phys 8: 1981-1997, 1982.

18 Joiner MC, Van der Kogel AJ: The linear-quadratic approach to fractionation and calculation of isoeffect relationships, in Steel GG (ed): Basic clinical radiobiology. New York, Oxford University Press, 106-112, 1997.

19 Milano MT, Vokes EE, Salama JK, Stenson KM, Kao J, Witt ME, Mittal BB, Argiris A, Weichselbaum RR and Haraf DJ: Twice-daily reirradiation for recurrent and second primary headand-neck cancer with gemcitabine, paclitaxel, and 5-fluorouracil chemotherapy. Int J Radiat Oncol Biol Phys 61: 1096-1106, 2005.

20 Müller AC, Diestelhorst A, Kuhnt T, Kühn R, Fornara P, Scholz HJ, Dunst J and Zietman AL: Organ-sparing treatment of advanced bladder cancer: paclitaxel as a radiosensitizer. Strahlenther Onkol 183: 177-183, 2007.

21 Chen LY, Huang CC, Tsou YA, Bau DT and Tsai MH: Prognostic factor of severe complications in patients with hypopharyngeal cancer with primary concurrent chemoradiotherapy. Anticancer Res 35: 1735-1741, 2015.

22 Song JH, Jeong BK, Choi HS, Jeong H, Kang MH, Kang JH, Kim JP, Park JJ, Woo SH, Jang HS, Choi BO and Kang KM: Comparison of failure patterns between conventional and intensitymodulated radiotherapy for stage III and IV head and neck squamous cell carcinoma. Anticancer Res 35: 6833-6840, 2015.

23 Franco P, Potenza I, Schena M, Riva G, Pecorari G, Demo PG, Fasolis M, Moretto F, Garzaro M, Di Muzio J, Melano M, Airoldi M, Ragona R, Rampino M and Ricardi U: Induction chemotherapy and sequential concomitant chemo-radiation in locally advanced head and neck cancers: How induction-phase intensity and treatment breaks may impact on clinical outcomes. Anticancer Res 35: 6247-6254, 2015. 
24 Fujimoto Y, Kato S, Itoh Y, Naganawa S and Nakashima T: A phase I study of concurrent chemoradiotherapy using oral s-1 for head and neck cancer. Anticancer Res 34: 209-213, 2014.

25 Denis F, Garaud P, Bardet E, Alfonsi M, Sire C, Germain T, Bergerot $\mathrm{P}$, Rhein B, Tortochaux $\mathrm{J}$ and Calais G: Final results of the 94-01 French Head and Neck Oncology and Radiotherapy Group randomized trial comparing radiotherapy alone with concomitant radiochemotherapy in advanced-stage oropharynx carcinoma. J Clin Oncol 22: 69-76, 2004.

26 Cvek J, Knybel L, Skacelikova E, Stransky J, Matousek P, Zelenik K, Res O, Otahal B, Molenda L and Feltl D: Hyperfractionated stereotactic reirradiation for recurrent head and neck cancer. Strahlenther Onkol 192: 40-46, 2016.

27 Dornoff N, Weiß C, Rödel F, Wagenblast J, Ghanaati S, Atefeh $\mathrm{N}$, Rödel C and Balermpas P: Re-irradiation with cetuximab or cisplatin-based chemotherapy for recurrent squamous cell carcinoma of the head and neck. Strahlenther Onkol 191: 656664, 2015.

28 Pham A, Arora S, Wernicke AG, Kutler DI, Cohen M, Kuhel W, Trichter S, Nori D, Formenti SC and Parashar B. Cesium-131 brachytherapy in high risk and recurrent head and neck cancers: first report of long-term outcomes. J Contemp Brachytherapy 7: 445-452, 2015.
29 Hayashi Y, Nakamura T, Mitsudo K, Kimura K, Yamaguchi H, Ono T, Azami Y, Takayama K, Hirose K, Yabuuchi T, Suzuki M, Hatayama Y, Kikuchi Y, Wada H, Fuwa N, Hareyama M and Tohnai I: Re-irradiation using proton beam therapy combined with weekly intra-arterial chemotherapy for recurrent oral cancer. Asia Pac J Clin Oncol, 2016, in press.

30 Jeong S, Yoo EJ, Kim JY, Han CW, Kim KJ and Kay CS: Reirradiation of unresectable recurrent head and neck cancer: Using helical tomotherapy as image-guided intensity-modulated radiotherapy. Radiat Oncol J 31: 206-215, 2013.

31 Al-Wassia R, Vakilian S, Holly C, Sultanem K and Shenouda G: A retrospective study of head and neck re-irradiation for patients with recurrent or second primary head and neck cancer: the McGill University experience. J Otolaryngol Head Neck Surg 44: 31, 2015.

Received August 4, 2016

Revised August 18, 2016

Accepted August 19, 2016 